\title{
Status gingiva anak usia 14-15 tahun di daerah dataran tinggi dan di daerah pesisir pantai
}

\author{
${ }^{1}$ Jizel Zarra \\ ${ }^{2}$ Krista V. Siagian \\ ${ }^{2}$ Juliatri
}

\author{
${ }^{1}$ Kandidat Skripsi Program Studi Pendidikan Dokter Gigi Fakultas Kedokteran \\ ${ }^{2}$ Program Studi Pendidikan Dokter Gigi Fakultas Kedokteran \\ Universitas Sam Ratulangi Manado \\ Email: jizelzarra212@gmail.com
}

\begin{abstract}
Gingiva is prone to any disturbances. Poor dental and oral health can cause inflammation of the gingiva. Children aged 14-15 years have already permanent teeth that had fully grown. This study was aimed to obtain the gingival status of children aged between 1415 years old living in the highland and at the coastal area. This was a descriptive observational study with a cross sectional design. The study population was all students aged 14-15 years at SMP GMIM Rurukan and SMP PGRI Tandurusa (Junior high schools). Subjects were 30 students obtained by using purposive sampling. Data of gingival status were obtained from examination of gingival index according to Loe and Silness. The results showed that the gingival status of subjects living in the highland were mild inflammatory category $(66.7 \%)$ and moderate inflammatory category (33.3\%), whereas of those at the coastal area were mild inflammatory category (93.4\%) and moderate inflammatory category (3.3\%).
\end{abstract}

Keywords: gingival status, children 14-15 years, highland, coast

\begin{abstract}
Abstrak: Gingiva merupakan jaringan yang rentan terhadap berbagai gangguan. Buruknya kesehatan gigi dan mulut dapat menimbulkan peradangan gingiva. Pada kelompok usia 14-15 tahun anak telah memiliki gigi permanen yang sudah tumbuh lengkap dalam rongga mulut. Penelitian ini bertujuan untuk mengetahui status gingiva anak usia 14-15 tahun di daerah dataran tinggi dan di daerah pesisir pantai. Jenis penelitian ialah deskriptif observasional dengan desain potong lintang. Populasi penelitian ialah seluruh siswa berusia 14-15 tahun yang bersekolah di SMP GMIM Rurukan dan SMP PGRI Tandurusa. Subjek penelitian diambil sebanyak 30 siswa menggunakan purposive sampling. Pengumpulan data menggunakan formulir pemeriksaan status gingiva berdasarkan indeks gingiva Loe and Silness. Hasil penelitian mendapatkan status gingiva subjek di daerah dataran tinggi tergolong kategori inflamasi ringan $(66,7 \%)$ dan kategori inflamasi sedang $(33,3 \%)$, sedangkan status gingiva subjek di pesisir pantai tergolong kategori inflamasi ringan $(93,4 \%)$ dan kategori inflamasi sedang $(3,3 \%)$.
\end{abstract}

Kata kunci: Status gingiva, usia 14-15 tahun, dataran tinggi, pesisir pantai

Gingiva merupakan bagian dari mukosa mulut yang mengelilingi leher gigi yang sudah erupsi dan menutupi mahkota gigi yang tidak/belum erupsi, yang berfungsi sebagai struktur penunjang untuk jaringan di sekitarnya. Dalam istilah awam gingiva disebut gusi. Buruknya kesehatan gigi dan mulut dapat menimbulkan peradangan pada gingiva yang disebut gingivitis. Tanda dan gejala gingivitis seperti adanya kemerahan, bengkak, dan terjadi pendarahan kecil pada gingiva saat menyikat gigi. ${ }^{1,2}$

Berdasarkan data Riset Kesehatan Dasar (RISKESDAS) tahun 2013, masalah 
gigi dan mulut termasuk penyakit gingiva di Provinsi Sulawesi Utara yaitu sebesar 31,6\%. Penelitian sebelumnya yang dilakukan oleh Mustainah menunjukkan status $\mathrm{OHI}-\mathrm{S}$ remaja di daerah pegunungan sebesar 2,25\% dan di daerah pesisir pantai lebih rendah yaitu sebesar $1,13 \%$. Hal ini menunjukkan bahwa penduduk yang secara geografis letak kediamannya berbeda, mempunyai status $\mathrm{OHI}-\mathrm{S}$ dan gingiva yang berbeda pula jika dihubungkan dengan kadar fluor air dan makanan yang dikonsumsi. ${ }^{3,4}$

Sulawesi Utara merupakan salah satu provinsi yang terbentang dengan rangkaian pegunungan, dataran tinggi dan pesisir pantai yang luas. Sebagian besar penduduk dataran tinggi memanfaatkan hasil alam seperti bertani dan berkebun sebagai bahan konsumsi sehari-hari di antaranya sayursayuran dan buah-buahan. Penduduk pesisir pantai sebagian besar bergantung pada hasil tambak dan perikanan yang ada. Ikan dan air yang banyak dikonsumsi mengandung fluor yang memiliki tingkat keasaman yang rendah ( $\mathrm{pH}$ tinggi) yang dapat membuat tulang dan gigi menjadi kuat, meningkatkan ketahanan gigi, memperbaiki kerusakan lapisan gigi, dan mencegah sisa karbohidrat dalam mulut menjadi asam, sehingga dapat mencegah terbentuknya plak yang selanjutnya dapat menyebabkan gingivitis. Dapat dikatakan bahwa terdapat perbedaan letak geografis, jenis makanan dan kadar fluor antara penduduk dataran tinggi dan pesisir pantai. ${ }^{5-8}$

Anak remaja berusia 14-15 tahun telah memiliki gigi permanen yang sudah ada sejak 3-9 tahun dalam rongga mulut, sehingga pemeriksaan gingiva akan lebih bermakna dibandingkan dengan anak berusia 12 tahun. Penelitian di Indonesia mengenai status gingiva belum banyak diteliti pada kelompok usia tersebut, padahal penelitian tersebut diperlukan untuk menilai keadaan kesehatan gigi termasuk keadaan status gingiva.,

Penelitian ini bertujuan untuk mendapatkan status gingiva anak usia 1415 tahun di daerah dataran tinggi dan di daerah pesisir pantai.

\section{BAHAN DAN METODE PENELITIAN}

Jenis penelitian ialah deskriptif dengan desain potong lintang. Penelitian ini dilaksanakan di daerah dataran tinggi Rurukan Tomohon dan di daerah pesisir pantai Desa Tandurusa Kecamatan Airtembaga pada bulan Juli 2016. Responden penelitian ialah 30 siswa usia 14-15 tahun yang bersekolah di SMP GMIM dan 30 siswa SMP PGRI yang diperoleh dengan metode purposive sampling. Pengambilan data diperoleh melalui formulir pemeriksaan dari responden penelitian untuk melihat status gingiva pada siswa usia 14-15 tahun di daerah dataran tinggi dan di pesisir pantai.

\section{HASIL PENELITIAN}

Distribusi responden berdasarkan jenis kelamin dapat dilihat pada Tabel 1 sedangkan berdasarkan usia pada Tabel 2 .

Tabel 1. Distribusi responden berdasarkan jenis kelamin di dataran tinggi dan di pesisir pantai

\begin{tabular}{ccrrrrrr}
\hline Jenis Kelamin & \multicolumn{2}{c}{ Dataran Tinggi } & \multicolumn{2}{c}{ Pesisir Pantai } & & \multicolumn{2}{c}{ Total } \\
\cline { 2 - 4 } & $\mathrm{n}$ & $\%$ & $\mathrm{n}$ & $\%$ & $\mathrm{n}$ & $\%$ \\
\hline Laki-Laki & 16 & 53,3 & 8 & 26,7 & 24 & 40 \\
Perempuan & 14 & 46,7 & 22 & 73,3 & 36 & 60 \\
Total & 30 & 100,0 & 30 & 100,0 & 60 & 100 \\
\hline
\end{tabular}

Tabel 2. Distribusi responden berdasarkan usia di dataran tinggi dan pesisir pantai

\begin{tabular}{|c|c|c|c|c|c|c|}
\hline \multirow{2}{*}{$\begin{array}{l}\text { Usia } \\
\text { (Tahun) }\end{array}$} & \multicolumn{2}{|c|}{ Dataran Tinggi } & \multicolumn{2}{|c|}{ Pesisir Pantai } & \multicolumn{2}{|c|}{ Total } \\
\hline & n & $\%$ & n & $\%$ & n & $\%$ \\
\hline 14 Tahun & 21 & 70 & 21 & 70 & 42 & 70 \\
\hline 15 Tahun & 9 & 30 & 9 & 30 & 18 & 30 \\
\hline Total & 30 & 100 & 30 & 100 & 60 & 100 \\
\hline
\end{tabular}

Tabel 3. Distribusi responden berdasarkan kategori status gingival

\begin{tabular}{crrrrrr}
\hline Status Gingiva & \multicolumn{2}{c}{ Dataran Tinggi } & \multicolumn{2}{c}{ Pesisir Pantai } & \multicolumn{2}{c}{ Total } \\
\cline { 2 - 5 } & $\mathrm{n}$ & $\%$ & $\mathrm{n}$ & $\%$ & $\mathrm{n}$ & $\%$ \\
\hline Normal & 0 & 0 & 1 & 3,3 & 1 & 1,7 \\
Inflamasi Ringan & 20 & 66,7 & 28 & 93,4 & 48 & 80 \\
Inflamasi Sedang & 10 & 33,3 & 1 & 3,3 & 1 & 18,3 \\
Inflamasi Berat & 0 & 0 & 0 & 0 & 0 & 0 \\
Total & 30 & 100,0 & 30 & 100,0 & 60 & 100,0 \\
\hline
\end{tabular}


Tabel 4. Distribusi status gingiva berdasarkan jenis kelamin di dataran tinggi

\begin{tabular}{|c|c|c|c|c|c|c|c|c|c|c|}
\hline \multirow{4}{*}{$\begin{array}{c}\text { Jenis } \\
\text { Kelamin }\end{array}$} & \multicolumn{6}{|c|}{ Dataran Tinggi } & & & \multicolumn{2}{|c|}{ Total } \\
\hline & \multirow{2}{*}{\multicolumn{2}{|c|}{ Normal }} & \multirow{2}{*}{\multicolumn{2}{|c|}{$\begin{array}{l}\text { Inflamasi } \\
\text { Ringan }\end{array}$}} & \multirow{2}{*}{\multicolumn{2}{|c|}{$\begin{array}{c}\text { Inflamasi } \\
\text { Sedang }\end{array}$}} & \multirow{2}{*}{\multicolumn{2}{|c|}{$\begin{array}{l}\text { Inflamasi } \\
\text { Berat }\end{array}$}} & & \\
\hline & & & & & & & & & & \\
\hline & $\mathrm{n}$ & $\%$ & n & $\%$ & n & $\%$ & n & $\%$ & $\mathrm{n}$ & $\%$ \\
\hline L & 0 & 0 & 9 & 30 & 7 & 23,3 & $\overline{0}$ & 0 & 16 & 53,3 \\
\hline P & 0 & 0 & 11 & 36,7 & 3 & 10 & 0 & 0 & 14 & 46,7 \\
\hline Total & 0 & & 20 & & 10 & & 0 & & 30 & 100 \\
\hline
\end{tabular}

Tabel 5. Distribusi status gingiva berdasarkan jenis kelamin di pesisir pantai

\begin{tabular}{|c|c|c|c|c|c|c|c|c|c|c|}
\hline \multirow{4}{*}{$\begin{array}{c}\text { Jenis } \\
\text { Kelamin }\end{array}$} & \multicolumn{8}{|c|}{ Pesisir Pantai } & \multicolumn{2}{|c|}{ Total } \\
\hline & \multirow{2}{*}{\multicolumn{2}{|c|}{ Normal }} & \multirow{2}{*}{\multicolumn{2}{|c|}{$\begin{array}{l}\text { Inflamasi } \\
\text { Ringan }\end{array}$}} & \multirow{2}{*}{\multicolumn{2}{|c|}{$\begin{array}{l}\text { Inflamasi } \\
\text { Sedang }\end{array}$}} & \multirow{2}{*}{\multicolumn{2}{|c|}{$\begin{array}{c}\text { Inflamasi } \\
\text { Berat }\end{array}$}} & & \\
\hline & & & & & & & & & & \\
\hline & n & $\%$ & n & $\%$ & n & $\%$ & n & $\%$ & n & $\%$ \\
\hline L & 1 & 3,3 & 7 & 23,3 & 0 & 0 & 0 & 0 & 8 & 26,7 \\
\hline$P$ & 0 & 0 & 21 & 70 & 1 & 3,3 & 0 & 0 & 22 & 73,3 \\
\hline Total & & & 28 & & 1 & & 0 & & 30 & 100 \\
\hline
\end{tabular}

Tabel 6. Distribusi status gingiva berdasarkan usia di dataran tinggi

\begin{tabular}{|c|c|c|c|c|c|c|c|c|c|c|}
\hline \multirow{3}{*}{$\begin{array}{c}\text { Usia } \\
\text { (Tahun) }\end{array}$} & \multicolumn{8}{|c|}{ Dataran Tinggi } & \multicolumn{2}{|c|}{ Total } \\
\hline & & & & & & & & & & \\
\hline & $\mathrm{n}$ & $\%$ & $\mathrm{n}$ & $\%$ & $\mathrm{n}$ & $\%$ & $\mathrm{n}$ & $\%$ & $\mathrm{~N}$ & $\%$ \\
\hline 14 & 0 & 0 & 16 & 53,3 & 5 & 16,7 & $\overline{0}$ & 0 & 21 & 70 \\
\hline 15 & 0 & 0 & 4 & 13,3 & 5 & 16,7 & 0 & 0 & 9 & 30 \\
\hline Total & 0 & & 20 & & 10 & & 0 & & 30 & 100 \\
\hline
\end{tabular}

Tabel 7. Distribusi status gingiva berdasarkan usia di pesisir pantai

\begin{tabular}{|c|c|c|c|c|c|c|c|c|c|}
\hline \multirow{3}{*}{$\begin{array}{l}\text { Usia } \\
\text { (Tahun) }\end{array}$} & \multicolumn{7}{|c|}{ Pesisir Pantai } & \multicolumn{2}{|c|}{ Total } \\
\hline & Normal & & $\begin{array}{l}\text { amasi } \\
\text { agan }\end{array}$ & & & & & & \\
\hline & n $\quad \%$ & $\mathrm{n}$ & $\%$ & $\mathrm{n}$ & $\%$ & $\mathrm{n}$ & $\%$ & $\mathrm{n}$ & $\%$ \\
\hline 14 & 3,3 & 19 & 63,3 & 1 & 3,3 & 0 & 0 & 21 & 70 \\
\hline 15 & 0 & 9 & 30 & 0 & 0 & 0 & 0 & 9 & 30 \\
\hline Total & 1 & 28 & & 1 & & 0 & & 30 & 100 \\
\hline
\end{tabular}

\section{BAHASAN}

Distribusi responden berdasarkan jenis kelamin di daerah dataran tinggi dan pesisir pantai (Tabel 1) menunjukkan responden perempuan $(60 \%)$ lebih banyak dibandingkan laki-laki (40\%). Hal ini disebabkan pada saat penelitian berlangsung responden perempuan lebih banyak yang memenuhi kriteria inkulsi dibandingkan laki-laki, seperti hadir di tempat penelitian dan bersedia mengikuti seluruh prosedur penelitian yang dilaksanakan di sekolah. 
Distribusi responden berdasarkan usia 14-15 tahun di daerah dataran tinggi dan pesisir pantai (Tabel 2) menunjukkan responden yang berusia 14 tahun (70\%) lebih banyak dibandingkan usia 15 tahun $(30 \%)$. Hal ini sejalan dengan penelitian sebelumnya yang dilakukan oleh Lesar $^{3}$ tentang status kebersihan gigi dan mulut dan status gingiva anak remaja tahun 2013, menunjukkan responden yang berusia 14 tahun $(55,5 \%)$ lebih banyak dibandingkan responden yang berusia 15 tahun $(12,7 \%)$.

Distribusi responden berdasarkan kategori status gingiva di daerah dataran tinggi dan pesisir pantai (Tabel 3), menunjukkan status gingiva di daerah dataran tinggi dengan status gingiva inflamasi ringan sebanyak $66,7 \%$ (rata-rata nilai sebesar 0,6) dan status gingiva inflamasi sedang sebanyak 33,3\% (rata-rata nilai sebesar 1,2). Berbeda dengan daerah pesisir pantai yang menunjukkan status gingiva dengan inflamasi ringan sebanyak 93,4\% (rata-rata nilai sebesar 0,4) dan gingiva dengan inflamasi sedang sebanyak $3,3 \%$ (rata-rata nilai sebesar 1,3). Hal ini sejalan dengan penelitian sebelumnya yang dilakukan oleh Fitriyanti et al. ${ }^{10}$ tentang kesehatan status gingiva di daerah pesisir dan non pesisir di Kabupaten Jepara tahun 2012. Daerah pesisir pantai termasuk dalam status gingiva inflamasi ringan sebesar $92 \%$ dan inflamasi sedang $8 \%$, sedangkan di daerah non pesisir status gingiva inflamasi ringan sebesar $42 \%$, sedang $52 \%$ dan berat $6 \%$.

Distribusi status gingiva berdasarkan jenis kelamin di daerah dataran tinggi (Tabel 4) menunjukkan status gingiva dengan inflamasi ringan lebih banyak ditemukan pada responden perempuan $(36,7 \%)$ dibandingkan laki-laki (30\%) sedangkan status gingiva dengan inflamasi sedang lebih banyak ditemukan pada responden laki-laki $(23,3 \%)$ dibandingkan perempuan $(10 \%)$.

Distribusi status gingiva berdasarkan jenis kelamin di daerah pesisir pantai (Tabel 5) menunjukkan status gingiva dengan inflamasi ringan lebih banyak ditemukan pada responden perempuan
(70\%) dibandingkan laki-laki (23,3\%). Penelitian sebelumnya yang dilakukan di Pakistan oleh Hiremath et al. ${ }^{11}$ tahun 20102011 tentang prevalensi gingivitis anak usia 11-13, dari 928 responden menunjukkan bahwa prevalensi gingivitis lebih banyak pada laki-laki (82\%) dibandingkan perempuan $(76 \%)$. Hal ini menunjukkan bahwa seiring bertambahnya waktu gingivitis dapat terjadi pada siapa saja baik laki-laki maupun perempuan.

Distribusi status gingiva berdasarkan usia di daerah dataran tinggi (Tabel 6) menunjukkan status gingiva dengan inflamasi ringan lebih banyak ditemukan pada responden dengan usia 14 tahun (76,2\%) dibandingkan 15 tahun $(44,4 \%)$. Status gingiva dengan inflamasi sedang pada usia 14 tahun sebanyak 22,8\% dan usia 15 tahun sebanyak 55,6\%. Hal ini disebabkan pada saat penelitian berlangsung responden yang berusia 14 tahun lebih banyak dibandingkan 15 tahun.

Distribusi status gingiva berdasarkan usia di daerah pesisir pantai (Tabel 7) menunjukkan status gingiva dengan inflamasi ringan lebih banyak ditemukan pada responden usia 14 tahun $(63,3 \%)$ dibandingkan usia 15 tahun (30\%). Hal ini sejalan dengan penelitian yang dilakukan oleh Thamrin ${ }^{12}$ tentang perdarahan gingiva disertai kalkulus pada usia 12-14 tahun di Kabupaten Luwu tahun 2015 lebih banyak dialami pada anak usia 14 tahun sebanyak $57,1 \%$. Juga penelitian yang dilakukan oleh Lesar $^{3}$ mendapatkan bahwa usia 12-15 tahun merupakan usia kritis untuk pengukuran indikator penyakit periodontal anak remaja.

Hasil penelitian yang dilakukan menunjukkan status gingiva anak usia 1415 tahun di daerah pesisir pantai sebagian besar termasuk pada kategori inflamasi ringan. Berbeda dengan di dataran tinggi, didapatkan sebagian anak memiliki kategori gingiva dengan inflamasi ringan dan sebagiannya lagi memiliki kategori gingiva dengan inflamasi sedang. Inflamasi gingiva disebabkan oleh akumulasi plak yang dapat membentuk kalkulus dan dapat mengakibatkan terjadinya peradangan 
gingiva atau gingivitis. ${ }^{13}$

Gingivitis terjadi akibat kesehatan gigi dan mulut yang buruk atau tidak memadai, ditandai dengan adanya kemerahan, bengkak dan cenderung terjadi pendarahan pada gingiva. Beberapa studi epidemiologi menunjukkan bahwa gingivitis dari berbagai tingkat keparahannya umumnya ditemukan pada anak remaja. Pencegahan gingivitis dapat diatasi dengan cara alamiah yaitu menyikat gigi dengan teratur, scalling, dan tidak mengonsumsi makanan yang dapat menyebabkan karies dan gingivitis.

Masyarakat yang tinggal di daerah pesisir pantai banyak mengonsumsi ikan laut hasil dari tambak dan melaut mereka. Ikan yang dikonsumsi masyarakat memiliki kandungan fluor atau $\mathrm{pH}$ yang tinggi yang dapat membuat tulang dan gigi menjadi kuat. Pada masyarakat yang tinggal di daerah dataran tinggi sebagian besar menggunakan sayur-sayuran sebagai bahan konsumsi mereka sehari-hari; hal ini dapat dilihat karena sebagian besar masyarakat bermata pencaharian sebagai petani. Jarak antara tempat penelitian di daerah dataran tinggi dengan pusat kota tidak terlalu jauh, hal ini memungkinkan bahwa masyarakat juga banyak mengonsumsi makanan kariogenik. Makanan kariogenik mengandung fluor atau $\mathrm{pH}$ yang rendah (keasaman tinggi) sehingga berpotensi menyebabkan terjadinya akumulasi plak yang dapat menimbulkan peradangan pada gingiva dan erosi pada gigi. ${ }^{5,8}$

\section{SIMPULAN}

Dari hasil penelitian dan bahasan dapat disimpulkan bahwa status gingiva anak di daerah dataran tinggi lebih rendah dibandingkan di daerah pesisir pantai.

\section{SARAN}

1. Bagi anak yang memiliki masalah pada gingiva agar dapat menjaga kesehatan gigi dan mulut dengan menyikat gigi secara teratur dan benar . Bagi anak yang sudah memiliki kebiasaan baik tentang kesehatan gigi dan mulut agar dapat dipertahankan.
2. Bagi Dinas Kesehatan perlu adanya peningkatan sarana kesehatan gigi dan mulut di daerah dataran tinggi dan di pesisir pantai.

3. Dapat dijadikan bahan acuan untuk penelitian lebih lanjut mengenai perbandingan status gingiva remaja di dataran tinggi dan di pesisir pantai dengan faktor-faktor yang lebih bervariasi dengan jumlah responden yang lebih banyak.

\section{DAFTAR PUSTAKA}

1. Harty FJ, Ogston R. Kamus Kedokteran Gigi. Jakarta: EGC, 2012; p. 138-40

2. Karim C, Gunawan P, Wicaksono D. Gambaran status gingiva pada anak usia sekolah dasar di SD GMIM Tonsea Lama. Manado. 2013. [cited 25 Februari 2016]. Available from: http: //ejournal.unsrat.

ac.id/index.php/egigi/article/view/3227

3. Lesar AM, Pangemanan DHC, Zuliari K. Gambaran status kebersihan gigi dan mulut serta status gingiva pada anak remaja di SMP Advent Watulaney Kabupaten Minahasa. 2013. [cited 2 Maret 2016]. Available from: http://ejournal.

unsrat.ac.id/index.php/egigi/article/vie wFile/8823/9187 .

4. Mustainah I. Perbedaan karies gigi dan kadar fluor air sumur siswa SMA di kecamatan Asembagus (daerah pantai) dan di Kecamatan Sukosari (daerah gunung). [cited 2 Maret 2016]. Bagian Ilmu Kesehatan Gigi Masyarakat Fakultas Kedokteran Gigi Universitas Jember. 2012. Availabe from: :http://repository.

unej.ac.id/bitstream/handle/123456789/ 3845/Skripsi.pdf?sequence $=1$.

5. Siregar CN. Partisipasi masyarakat dan nelayan dalam mengurangi pencemaran air laut di kawasan pantai Manado Sulawesi Utara. [cited 3 Maret 2016]. Institut Teknologi Bandung. 2014. Available from: http://journals. itb.ac.id/index.php/sostek/article/view/1 131.

6. Sondang P, Harmada T. Menuju gigi dan mulut sehat, pencegahan dan pemeliharaan. [cited 15 Maret 2016]. Medan: USU Press, 2008; p. 22. 
Available from: http://usupress. usu.ac.id/files/Menuju\%20Gigi\%20dan \%20Mulut\%20Sehat\%20_Pencegahan $\% 20$ dan\%20Pemeliharaan_Normal_b ab\%201.pdf

7. Hartati S, Rachmat IMK. Seri Panduan Belajar dan Evaluasi Ilmu Pengetahuan Sosial. Grasindo. [internet]. [cited 15 Maret 2016]. Available from: https://books.

google.co.id/books?id=CWZ5SmHsyj wC\&pg=PA10\&dq=dataran+tinggi+ad alah\&hl=id\&sa=X\&ei=vSowU5yCFM OXrgeWwICQCg\&redir_esc $=\mathrm{y} \# \mathrm{v}=\mathrm{one}$ page $\& q \& \mathrm{f}=$ false.

8. Widyatmati W, Natalia D. Geografi. Grasindo. [Internet]. [cited 17 Maret 2016. Available from: https://books.google.co.id/books?id=8 MzpMT8mjyoC\&pg=PT122\&dq=data ran+tinggi+adalah $\& \mathrm{hl}=\mathrm{id} \& \mathrm{sa}=\mathrm{X} \& \mathrm{ei}=\mathrm{v}$ SowU5yCFMOXrgeWwICQCg\& redir _esc $=\mathrm{y} \# \mathrm{v}=$ onepage $\& \mathrm{q} \& \mathrm{f}=$ false.

9. Wowor VG, Wicaksono D, Rattu Hubungan antara status kebersihan mulut dengan karies siswa sekolah menengah atas Negeri 1 Manado. 2013. [cited 17 Maret 2016]. Available from: http://ejournal. unsrat.ac.id/index.php/egigi/article/vie w/3216.

10. Fitriyanti A, Susilowati A, Darjono U. Perbedaan pola konsumsi ikan dan status kesehatan gigi dan mulut pada anak usia sekolah dasar (7-12th) di daerah pesisir dan non pesisir Kabupaten Jepara. 2012. [cited 1 Agustus 2016]. Available from: http://jurnal.unissula.ac.id/ index.php/odj/article/view/263.

11. Hiremath V, Mishra N, Patil AG, Sheetal A, Kumar S. Prevalence of gingivitis among children living in Bhopal. J Oral Health; 2012 .p. 118-20. [cited 1 Agustus 2016]. Available from: http://www.johcd.

org/pdf/Sept_Dec2012/03_JOHCD\%2 0(Prevalence\%20of\%20gingivitis\%20a mong\%20children)\%20(2).pdf.

12. Thamrin NA. Kebutuhan perawatan periodontal pada remaja SMPN 1 Belopa usia 12-14 tahun di kabupaten Luwu. 2015. [cited 1 Agustus 2016]. Available from: http://repository.unhas.ac.id/bitstream/h andle/123456789/16427/SKRIPSI,.pdf ?sequence $=1$.

13. Sasea A, Lampus BS, Supit A. Gambaran status kebersihan rongga mulut dan status gingiva pada mahasiswa dengan gigi berjejal. 2013. [cited 1 Agustus 2016]. Available from: http://ejournal. unsrat.ac.id/index.php/egigi/article/vie w/1930. 